\title{
Investigação de Teste de Usabilidade para Aplicações Móveis
}

\author{
Huanna R. Nascimento*, Plínio Roberto Souza Vilela
}

\section{Resumo}

O objetivo final desse projeto é o desenvolvimento de uma metodologia de avaliação de usabilidade em um contexto de aplicações moveis que possa ser aplicada de forma geral em qualquer aplicativo para telefone celular. Este trabalho compreende a primeira etapa desse projeto que se constitui no levantamento de um conjunto de métricas que é desejável que uma aplicação contemple para que seja bem avaliada quanto a sua usabilidade. Para o levantamento dessas métricas foi usado como base o artigo "Usability Metric Framework for Mobile Phone Application" escrtito por Azham Hussain e Maria Kutar, e de outras fontes bibliográficas, além da elaboração de duas pesquisas de levantamento que buscaram identificar os principais problemas encontrados pelos usuários e validar as métricas encontradas.

\section{Palavras-chave:}

Usabilidade, Aplicações moveis, Teste de Usabilidade.

\section{Introdução}

Frequentemente encontramos problemas ou incômodos no uso de aplicações móveis e nos indagamos como esses erros não foram notados previamente. Ocorre que muitos desses problemas, percebidos normalmente por usuários, encontram-se "escondidos" no sistema, principalmente aos olhos do desenvolvedor, que tende a idealizar o funcionamento da sua aplicação.Com intuito de minimizar a ocorrência desses problemas é relevante que seja feita uma avaliação da usabilidade que priorize a experiencia do usuário durante o uso da aplicação móvel, de forma a tornar esses aplicativos fáceis de utilizar e flexíveis, mantendo a integridade dos dados a serem manipulados e possuindo uma interface simples e intuitiva, que ofereça como resposta os resultados esperados a cada ação.

Este projeto visa propor um método para que a avaliação de usabilidade citada acima possa ser realizada, de forma que uma aplicação móvel, quando submetida a ela, obtenha uma "nota" que diz o quanto aquela aplicação atende aos requisitos de usabilidade propostos pelas métricas levantadas.

\section{Resultados e Discussão}

Para atingir os objetivos propostos e testar as métricas levantadas no artigo "Usability Metric Framework for Mobile Phone Application" (Hussain \& Kutar, 2015), realizou-se primeiramente o levantamento bibliográfico, e posteriormente uma pesquisa de levantamento com o intuito de identificar tendências e comportamentos predominantes em um grupo de usuários aleatório. A partir dos dados obtidos, foi definida uma lista com métricas de usabilidade, assim como uma base de cálculo correspondente a cada uma. Essas métricas foram validadas a partir de uma segunda pesquisa de levantamento, onde foram eleitos três aplicativos de divulgação de eventos e venda de ingressos, e foram selecionados usuários para responder algumas perguntas quanto a sua usabilidade.

O resultado obtido neste projeto compreende a um conjunto composto por 27 métricas que possuem 0 intuito de avaliar o quanto uma determinada aplicação móvel atende a alguns requisitos de usabilidade.

\section{Conclusões}

Os resultados obtidos com essas métricas devem ser considerados como uma avaliação geral de usabilidade para aplicações moveis, alguns aspectos específicos que dependem da subjetividade do usuário devem ser avaliados de outra forma, considerando características como público alvo e segmento trabalhado. A partir desta constatação, o conjunto de métricas obtidos foi utilizado como método de avaliação de usabilidade em três aplicações moveis do mesmo segmento. O desempenho de cada aplicação foi comparado com a percepção dos usuários, identificada na pesquisa de levantamento, e com a nota que aquela aplicação possui na "Play Store" (serviço de distribuição digital de aplicativos da Google). Desta forma foi possível observar que o desempenho de cada aplicação, quando submetida ao conjunto de métricas elaborado, é condizente com a percepção dos usuários durante $\mathrm{o}$ uso e com a nota que aquela aplicação possui na "Play Store". A partir de tal resultado podemos constatar que o conjunto de métricas definidos nesse projeto pode auxiliar no processo de avaliação de usabilidade para aplicações moveis,

\section{Agradecimentos}

A UNICAMP, seu corpo docente, direção e administração, por proporcionarem um ambiente solido de aprendizagem e desenvolvimento.

- meu professor orientador Plínio Roberto Souza Vilela, pelo empenho dedicado ao meu projeto de pesquisa.

Basili, V. R. (2002). Goal Question Metric Paradigm. Em J. J. Marciniak, Encyclopedia of Software Engineering, 2 Volume Set (p. 1584). USA: WileyInterscience.

Hussain, A., \& Kutar, M. (12 de janeiro de 2015). Usability Metric Framework for Mobile Phone Application. Reino Unido. Fonte: Researchgate: https://www.researchgate.net/publication/267368031_Usability_Metric_Frame work_for_Mobile_Phone_Application 